\title{
POLÍTICAS LINGUÍSTICAS E ENSINO DE LÍNGUA(S) DE FRONTEIRA NA ESCOLA ${ }^{1}$
}

\section{LINGUISTIC POLICIES AND EDUCATION OF BORDER LANGUAGE(S) IN SCHOOL}

\author{
Simone Beatriz Cordeiro Ribeiro ${ }^{2}$
}

\begin{abstract}
RESUMO: Este estudo deriva de uma pesquisa de doutorado desenvolvida no município de Guaíra, Paraná, sobre o ensino e a aprendizagem da Língua Espanhola enquanto Língua de Fronteira. Como Guaíra faz fronteira com o Paraguai e recebe muitos alunos que não falam a Língua Portuguesa, buscou-se linvestigar mais a fundo essa relação. Paralelamente à observação participante, se realizaram trinta e três entrevistas semiestruturadas para gerar os dados do estudo. Através das entrevistas, os participantes contribuíram com suas percepções e conhecimentos sobre a Língua Espanhola, a situação fronteiriça com o Paraguai, as festividades locais oriundas das crenças, culturas e tradições deste país e a relevância do ensino dessa Língua no município. A pesquisa teve como foco as Políticas e Planificações Linguísticas (CALVET, 2007; OLIVEIRA, 2005, 2010 e 2013; RAJAGOPALAN, 2013) e o Ensino de Língua(s) de Fronteira (STURZA, 2006 e 2010; RIBEIRO, 2015), em que a situação enunciativa do campo de estudo se desenvolve por meio da comunicação enquanto um representativo de vozes que entram em contato e conflito pela expressão de línguas e de culturas existentes em ambos os lados da fronteira física.
\end{abstract}

PALAVRAS-CHAVE: Políticas Linguísticas; Língua(s) de Fronteira; Fronteira Geográfica Enunciativa.

ABSTRACT: This study comes from a doctoral research developed in the municipality of Guaira, Paraná, that deals with the teaching and learning of the Spanish Language as a Border Language. Because Guaira borders with Paraguay, and receives many students who don't speak the Portuguese language, an on-site research was developed, and through participant observation, thirty-three semi-structured interviews were conducted, aiming to generate data for the study. Through the interviews, the participants contributed with their perceptions and knowledge about the Spanish language, the border situation with Paraguay, the local festivities stemming from the beliefs, cultures and traditions of this country, as well as the relevance of the teaching of that language in the municipality. The research focused on Applied Linguistics, Linguistic Policies and Plans (CALVET, 2007, OLIVEIRA, 2005, 2010

\footnotetext{
${ }^{1}$ Este artigo corresponde a um recorte da pesquisa de doutorado desenvolvida no município de Guaíra, Paraná, no Programa de Pós-Graduação em Letras, Linguagem e Sociedade, da UNIOESTE, campus de Cascavel, sob a orientação da professora Doutora Clarice Nadir von Borstel.

${ }^{2}$ Doutora em Letras pela Universidade Estadual do Oeste do Paraná. Professora adjunta de Português/Espanhol Adicional na Universidade Federal da Integração Latino-Americana.
} 
and 2013, RAJAGOPALAN, 2013) and Teaching of Border Language(s) (STURZA, 2006 and 2010; RIBEIRO, 2015). These references were selected because they study with scientific rigor how the enunciative situation develops through communication. The enunciation is object of research of this work because it represents how different voices come into contact and conflict by the expression of different languages and cultures, in both sides of the physical border, in Brazil and in Paraguay.

KEYWORDS: Linguistic Policies; Border language(s); Geographical Frontier Enunciative.

\section{Introdução}

O contexto atual suscita discussões sobre os direitos linguísticos, os planejamentos e as políticas linguísticas em conjunto com o ensino e com a aprendizagem de Línguas tanto Estrangeiras, de Imigrantes, como de Minorias, Indígenas, de Fronteira e Maternas. Sendo a política linguística a arte que administra as cogitações e as ações a respeito das línguas, conduzindo-as conforme o interesse público e o que se acredita ser importante para uma nação e o seu povo (RAJAGOPALAN, 2013), entende-se que "não é possível desvincular a língua do significado social e particular que assume para cada indivíduo" (OLIVEIRA, 2013, p. 3), haja vista a "intrínseca relação entre a linguagem, os indivíduos, suas identidades e a sociedade" (VON BORSTEL, 2013, p. 3).

Em regiões de fronteiras, em que limites cartográficos e enunciativos ditam regras econômicas, políticas, linguísticas e culturais em detrimento à prática da interculturalidade, essa relação estabelecida por von Borstel (2013), é bem mais complexa. A situação evidenciada pelas fronteiras e seus habitantes demonstram que estas vão além de limites cartográficos e de poder, são também espaços de interação linguístico-cultural, social, étnica e política, o que as caracteriza como fronteiras geográficas enunciativas ${ }^{3}$ (RIBEIRO, 2015).

A fronteira considerada como espaço de enunciação enfraquece a visão de Estado soberano e controlador, uma vez que as fronteiras sociais se fortalecem em virtude de novas necessidades de mercado que ultrapassam seus limites cartográficos, condição que, sob uma abordagem pós-moderna, possibilita um "espaço supranacional, determinado por todos os tipos de relações além de suas margens territoriais” (STURZA, 2006, p. 31).

\footnotetext{
${ }^{3}$ Ribeiro (2015) utiliza o termo "enunciativa" agregado à expressão "fronteira geográfica", por entender que a fronteira não é apenas geográfica ou enunciativa, mas sim a junção de ambas, pois a fronteira caracteriza-se pela interação comunicativa existente no representativo de vozes que permeiam o Brasil e os países de Língua Espanhola, tanto pela expressão de línguas como de culturas em contato e em conflito nos dois lados da fronteira. Portanto, a expressão fronteira geográfica enunciativa caracteriza-se pela interação comunicativa existente no espaço fronteiriço (RIBEIRO, 2015).
} 
Portanto, a presente discussão define-se pelo viés de fronteira geográfica enunciativa, pois a "fronteira se dá na e pela linguagem" (CAMPIGOTO, 2000, p. 17), e é preenchida, acima de tudo, de conteúdo social. Como nas fronteiras vivem etnias diferentes que, consequentemente, acabam entrando em contato linguístico, "os preconceitos, ao invés de serem eliminados, serão colocados em evidência" (CAMPIGOTO, 2000, p. 17). Isso porque a "fluidez das relações sociais fez surgir uma fronteira significada bem mais como espaço de interações e muito menos como um território delimitado" (STURZA, 2006, p. 29).

Assim, este texto corresponde a um recorte da pesquisa desenvolvida no município de Guaíra, Paraná, no Brasil, sobre o ensino e a aprendizagem da Língua Espanhola enquanto Língua de Fronteira. Guaíra está localizada na região oeste do Paraná, com fácil acesso à cidade de Salto del Guairá, Paraguai, uma vez que faz fronteira com este país. Apesar de as duas cidades serem separadas pelo Lago de Itaipu (Rio Paraná), pode-se ir e vir de uma a outra por meio de balsa a partir da cidade guairense, ou pela travessia da ponte Ayrton Senna, que tem 3.600 metros de extensão (divisa com o estado do Mato Grosso do Sul que faz fronteira seca com o Paraguai). Essa proximidade entre as duas regiões possibilita que a Língua Portuguesa e a Língua Espanhola entrem em contato, em conflito e que se misturem.

Em virtude dessa proximidade territorial, do comércio, do contato pessoal e institucional, uma vez que as escolas guairenses recebem muitos alunos hispano falantes que não falam a Língua Portuguesa, buscou-se investigar a presença da Língua Espanhola em Guaíra e a sua viabilidade na matriz curricular das instituições de ensino. Desse modo, por meio de uma pesquisa de campo e através de entrevistas realizadas, discutiu-se a importância e relevância da elaboração de uma política e de uma planificação linguísticas condizentes com a realidade de fronteira geográfica enunciativa vivenciada pelo município.

Para tanto, o estudo centra-se na Linguística Aplicada, com foco nos Direitos Linguísticos (Hamel, 2003), nas Políticas e Planificações Linguísticas conforme Calvet (2007), Oliveira (2010, 2004), Rajagopalan (2013), e von Borstel (2013), e nas Políticas de Ensino de Língua(s) de Fronteira (STURZA, 2006 e 2010; RIBEIRO, 2015), visto que a situação enunciativa, sob a perspectiva de fronteira geográfica enunciativa, desenvolve-se por meio da comunicação enquanto um representativo de vozes que entram em contato e conflito pela expressão de línguas e de culturas existentes em ambos os lados da fronteira física.

\section{Políticas linguísticas e ensino de línguas}


O ensino de línguas atrelado às políticas linguísticas tornou-se uma necessidade emergente, pois como afirma Rajagopalan, em entrevista concedida a Silva, Santos e Justina (2011, p. 5), "precisamos atrelar as duas coisas [política linguística e ensino de línguas] cada vez mais. A gente tem que pensar o ensino de línguas desde a abordagem, a metodologia a ser adotada em função da política linguística adotada no país”.

Para que as políticas e planificações da linguagem tornem-se efetivas é preciso respeitar os direitos linguísticos da comunidade ou do grupo, tanto em sua implementação como em sua defesa, pois "todo o direito linguístico se embasa, em última instância, na comunidade, e tem, portanto, um caráter coletivo" (HAMEL, 2003, p. 63).

Se atualmente discute-se a questão dos direitos linguísticos é porque na sociedade atual se faz necessária essa investigação e, como toda ação política repercute no âmbito da sociedade, é fundamental que em uma "democracia todos os cidadãos [tenham] o mesmo direito de expressar suas opiniões e serem consultados na tomada de decisões" (RAJAGOPALAN, 2013, p. 23). Assim, tanto o linguista como o cidadão merecem ser consultados quando se trata de políticas linguísticas, pois “o que está em jogo, a meu ver, é o futuro de uma língua nacional ou outras questões de tamanha importância sobre as quais todos os cidadãos - sem exceção - têm ou, se não tem, devem ter direito igual e irrestrito de opinar" (RAJAGOPALAN, 2013, p. 22), porque "quanto mais democrático for um dado sistema político, tanto mais ele proverá pela cidadania" (RAJAGOPALAN, 2013, p. 37).

Ao relacionar a linguística com a política, Rajagopalan (2013), afirma que a política linguística "tem tudo a ver, isto sim, com a política, entendida como uma atividade na qual todo cidadão - todos eles sem exceção - têm o direito e o dever de participar em condições de absoluta igualdade" (RAJAGOPALAN, 2013, p. 22), assim como têm o direito de expressar livremente suas opiniões, fazerem-se ouvir e serem respeitados, indiferentemente de como pareçam suas opiniões.

$\mathrm{Na}$ perspectiva do linguista citado, a política linguística compreende o campo da política e é o instrumento pelo qual as leis e mudanças linguísticas são elaboradas, providas e pensadas. A política linguística corresponde, de um lado, à "determinação das grandes decisões referentes às relações entre as línguas e a sociedade [de outro] à sua implementação" (CALVET, 2007, p. 11), a sua "transformação em realidade" (OLIVEIRA, 2013, p. 1). A política linguística é "um conjunto de escolhas conscientes referentes às relações entre língua(s) e vida social, o planejamento linguístico: a implementação prática de uma política linguística, em suma, a passagem ao ato" (CALVET, 2002, p. 145 - grifos do autor). 
Oliveira (2005), também concorda que a planificação linguística é a ação de pôr em prática as políticas linguísticas, pois é uma forma de intervenção e pode ter a participação de diferentes sujeitos da sociedade. Portanto, como destaca Rajagopalan (2013), a política linguística deve ser planejada com vistas a atender realmente as necessidades da comunidade ou ao grupo a que se destina, intensificando a participação dos cidadãos nas escolhas e determinações linguísticas e permitindo que as avaliações quanto à viabilidade e necessidade decididas pelas autoridades durante o planejamento linguístico, não sejam consideradas de maneira secundária, visto que intervenção "significa então: trabalho conjunto com as comunidades lingüísticas que conformam o país" (OLIVEIRA, 2005, p. 87).

É preciso que as necessidades e as urgências da sociedade sejam consideradas antes mesmo de se elaborar e promulgar uma lei de cunho político linguístico. Um planejamento engajado no âmbito social deverá impreterivelmente considerar as necessidades e as consequências de sua aplicação no seio da sociedade. Condição que determina

[...] a necessidade, em suma, de uma reforma linguística do país que permita uma reação coletiva positiva frente às novas demandas da globalização e da inclusão cultural e linguística. Essa reforma linguística passa pela organização das demandas dos falantes, através de suas representações, e do seu contato com o legislativo, onde estas demandas se transformam em indicação de ação, pela capacitação de órgãos de Estado diretamente envolvidos com a planificação linguística, como ministério de cultura, de educação, de ciência e tecnologia, secretarias estaduais e municipais, as escolas e as mídias (OLIVEIRA, 2013, p. 13).

Compreende-se que qualquer decisão política deve ter como ponto de partida o âmbito regional ou local. É preciso que o conhecimento já produzido e o a ser produzido sejam “adaptados para cada região, cada lugar, cada realidade. Cada um de nós, apesar de vivermos no mesmo país, temos realidades imediatas diferentes. Assim, como nossas circunstâncias são diferentes, nossas situações são diferentes" (SILVA, SANTOS e JUSTINA, 2011, p. 3), e fatores como a sociedade e as suas particularidades precisam ser considerados.

No caso das regiões fronteiriças, "as línguas da fronteira, ao enunciarem, significam uma política que as organiza e as distribui” (STURZA, 2006, p. 19). Esta distribuição é, muitas vezes, determinada por questões de interesse e/ou visões homogeneizadas que visam ao monolinguíssimo ou que consideram apenas as línguas a partir de conceitos de status.

\section{Fronteira geográfica enunciativa}


Quando se considera somente a cartografia como o âmbito que marca os limites físicos entre os territórios, a fronteira é vista apenas como o lugar que marca o início ou fim de um território. Mesmo que o faça de maneira simbólica, esses espaços são representativos, pois permitem que cada sujeito se comunique e se afirme em relação ao outro, definindo-se como, por exemplo, brasileiro, paraguaio, guairense, etc. Esses limites físicos ainda determinam condições de circulação e controle por parte do Estado, pois a fronteira "é sempre espaço de transgressão e contenção - transgressão pelos movimentos migratórios de ocupação social e política; contenção pelos mecanismos de limitações, de vigília e de controle" (STURZA, 2006, p. 19 - grifos nossos).

A linha de divisa (fronteira) entre os países "é um 'objeto' dito e escrito de vários modos. Podemos expressá-la como um traçado imaginário na periferia geográfica das nações, estabelecimento jurídico que separa os povos ou, ainda, ponto de junção entre nacionalidades" (CAMPIGOTO, 2006, p. 153). Além desses limites físico-demarcatórios de condições de poder, "a vida da fronteira, o habitar a fronteira [significa], para quem nela vive, muito mais, porque ela já se define em si mesma como um espaço de contato, um espaço em que se tocam culturas, etnias, línguas, nações" (STURZA, 2006, p. 26 - grifos da autora).

Assim, se, de um lado, tem-se a fronteira como espaço físico, de outro, tem-se a fronteira como espaço linguístico, condição que permite determinar essa dualidade como sendo uma fronteira geográfica (espaço físico, cartográfico) enunciativa (linguístico) (cf. RIBEIRO, 2015). Isso é possível porque o significado atribuído à "linha da fronteira depende dos 'olhos do observador"' (CAMPIGOTO, 2000, p. 11) e, no caso da fronteira geográfica enunciativa a Língua Estrangeira e/ou as Línguas Hibridas, como é o caso do Portunhol, passam a serem vistas como Línguas de Fronteira.

Neste caso, as fronteiras "são entendidas por aquelas áreas onde determinados grupos étnicos se reúnem/vivem, preservando suas culturas e, em muitos casos, suas línguas de "berço" para usar a categoria do RCNEI (2005)" (PEREIRA, 2011, p. 1). Para a pesquisadora citada, bem como para Sturza (2006) e Ribeiro (2015), as fronteiras são consideradas espaços de enunciação e de contato cultural, étnico, linguístico, etc., indo além dos limites físicos.

A fronteira geográfica enunciativa corresponde, como já destacado, às situações enunciativas que se desenvolvem por meio da comunicação enquanto um representativo de vozes que entram em contato e em conflito pela expressão de línguas e de culturas existentes em ambos os lados da fronteira física, uma vez que 
As fronteiras são espaços de trânsito: relações de convergência e divergência. As fronteiras são simbolicamente definidas pelo traçado geopolítico, mas são vividas socialmente. Há um espaço de enunciação fronteiriço. As relações entre as línguas se significam neste espaço de enunciação fronteiriço de modo diferenciado em relação a outros espaços de enunciação. As relações entre as línguas se significam no conflito, ou seja, no político. $\mathrm{O}$ espaço de enunciação fronteiriço revela que o espaço de circulação das línguas está condicionado à história das comunidades, sobretudo, a da economia local. O status de uma língua em relação à outra decorre da sua construção no imaginário dos sujeitos falantes e não se dá de modo simétrico (STURZA, 2010, p. 345-346).

Na fronteira geográfica enunciativa os sujeitos, ao se reconstruírem, transformam-se em novos sujeitos e, no caso de nações diferentes, a Língua Estrangeira passa a ser vista como uma Língua de Fronteira, em constante contato, conflito e hibridização, pois o espaço enunciativo fronteiriço é configurado pela integração de usuários e de línguas, que muitas vezes se misturam. Como é o caso do Portunhol, "um falar de solidariedade e de intercâmbio comercial” (RIBEIRO, 2015, p. 151) que ocorre em ambos os lados da Fronteira.

Ao transgredirem os limites geográficos e se constituírem como línguas de integração, a língua deixa de ser nacional, por se tratar de uma língua enunciativa de fronteira, suas necessidades e interações não são mais determinadas por contextos nacionais ou internacionais, mas sim por espaços de enunciação fronteiriços, pois as línguas de fronteira "se distribuem segundo uma organização própria, enunciada nas línguas ou sobre as línguas, nesse espaço de enunciação" (STURZA, 2006, p. 66).

\section{Breve traçado metodológico da pesquisa}

A pesquisa in loco desenvolvida na cidade de Guaíra realizou-se com o intuito de gerar dados sobre o ensino e a aprendizagem da Língua Espanhola nas instituições de ensino do referido município. Para tanto, elaborou-se um roteiro de entrevista semiestruturado que contemplou perguntas de cunho pessoal e sociocultural; função (em relação ao uso e entendimento da Língua Espanhola); e atitudes (ensino, aprendizagem e uso da Língua Espanhola; aspectos socioculturais e tradicionais do país vizinho festejados em Guaíra).

No total realizaram-se 33 (trinta e três) entrevistas semiestruturadas, que foram gravadas e, posteriormente, transcritas, durante o final do ano de 2013 e todo o ano de 2014. $\mathrm{Na}$ execução das entrevistas participaram diversos segmentos da sociedade guairense: equipes pedagógicas (coordenadores ou diretores) das instituições de ensino; alunos (CELEM e 
Colégios Privados); Professores; Participantes e Gestores da Festa da Nossa Senhora de Caacupét $^{4}$ e um representante da Secretaria Municipal de Educação.

Como o objetivo geral do estudo visava à relevância do ensino e da aprendizagem da Língua Espanhola nas instituições municipais de ensino guairense, a seleção dos Entrevistados ocorreu com vistas a ter no mínimo um representativo de cada uma dessas instituições e da Secretaria Municipal de Educação, ou seja, este grupo foi composto por 15 entrevistados. O quantitativo restante (18 entrevistas) foi preenchido com a participação de alunos, professores, participantes da festa em homenagem a Nossa Senhora de Caacupé e equipes pedagógicas de colégios estaduais e particulares, que fecharam o segundo grupo.

Através das entrevistas os participantes contribuíram com suas percepções e conhecimentos sobre a Língua Espanhola, a situação fronteiriça com o Paraguai, as festividades locais oriundas das crenças, culturas e tradições deste país e a importância do ensino dessa Língua no município.

Durante as entrevistas, a pesquisadora procurou de maneira clara e objetiva apresentar os pressupostos da pesquisa, a sua dimensão e as abordagens. Em cada visita, os participantes foram informados dos objetivos da investigação e foram convidados a colaborar. Os participantes receberam o Termo de Consentimento Livre e Esclarecido - TECLE, que foi lido em voz alta, explicado e na sequência assinado.

\section{A Língua Espanhola na fronteira: anseios, expectativas e a realidade dos Entrevistados}

Conforme o Entrevistado 01, a Língua Estrangeira que compõe a grade curricular das escolas municipais guairenses é a Língua Inglesa. Inclusive quando a pesquisadora chegava às escolas, se apresentava e informava o motivo de sua visita, relatando que se tratava de uma pesquisa de doutorado sobre a Língua Espanhola e o seu ensino no município, já lhe informavam que a língua presente na grade curricular era a Língua Inglesa.

Segundo as informações apresentadas durante as entrevistas, a decisão sobre a escolha Língua Estrangeira a ser ofertada na rede de ensino municipal partia da Secretaria Municipal de Educação, órgão responsável pelo ensino público do Ensino Fundamental I:

\section{ENTREVISTAD0.07 - R: 01}

\footnotetext{
${ }^{4}$ Conforme Ribeiro (2015), a Nossa Senhora de Caacupé é a padroeira do Paraguai e sempre foi festejada em Guaíra, Paraná. Trazida pelos primeiros moradores e funcionários da Companhia Matte Larangeira, que em sua maioria eram paraguaios, até os dias atuais é festejada e homenageada no dia 08 de dezembro. É uma tradição em Guaíra.
} 
Então assim, a grade da gente vem montada, né [...]. (Entrevista em 19/11/2014 - grifos da pesquisadora).

\section{ENTREVISTADO.05 - R: 01}

Depende da secretaria, pode sugerir, mas é ela quem decide por causa de funcionário. (Entrevista em 19/11/2014 - grifos da pesquisadora).

\section{ENTREVISTADO.15 - R: 01}

Tem reuniões com a equipe pedagógica, mas quem decide é a secretaria. A escola gostaria, mas depende da secretaria [...]. (Entrevista em 12/11/2014 grifos da pesquisadora).

\section{ENTREVISTADO.10 - R: 01}

É livre. A gente pode até opinar. Agora só como a gente depende (?) da prefeitura, né e da secretaria de educação, [...]. Mas temos o direito sim [opinar]. (Entrevista em 19/11/2014 - grifos da pesquisadora).

É possível observar, a partir dos recortes destacados, que as escolas podem opinar e sugerir sobre a Língua Estrangeira que gostariam de oferecer aos seus alunos, mas que isso somente acontece quando ocorrem reuniões com a Secretaria Municipal de Educação, instância que determina as disciplinas a comporem a matriz curricular municipal. Portanto, fica evidente a importância e o papel desempenhado por este órgão público.

Diante do exposto, destaca-se a relevância da participação desta comunidade nas escolhas das disciplinas que irão compor a grade curricular do Ensino Fundamental I e incentiva-se a Secretaria Municipal de Educação a ouvir e avaliar as sugestões das escolas. Sugere-se que essa instância deliberativa reflita, em conjunto com a comunidade, sobre o contexto político educacional atual do município, pois "não é a lei, não é o estado quem vai decidir qual ou quais línguas deverão ser ensinadas; é a comunidade, a partir de seus interesses e necessidades" (LEFFA, 2001, p. 339).

Assim, os Entrevistados, por meio de seus depoimentos, puderam expressar os seus anseios e perspectivas, sobre a relevância do ensino e a aprendizagem da Língua Espanhola no espaço de fronteira geográfica enunciativa em que se encontravam:

\section{ENTREVISTAD0.04 - R: 01}

Eu acho que a gente deveria ter nas escolas... é... a aula, a língua (?) em espanhol. Em vez da gente ter o inglês, que a gente tem o inglês, deveria adotar o espanhol. [...] Seria uma coisa muito interessante de ser implantado nas escolas, porque daí já é da realidade, quando a coisa é da realidade... os alunos de interessam mais e a aprendizagem é mais fácil, né. (Entrevista em 19/11/2014 - grifos da pesquisadora). 


\section{ENTREVISTADO.03 - R: 02}

Olha... olhando onde a gente tá aqui, nossa localização geográfica. Seria mais interessante tá trabalhando o espanhol, né, com os alunos, porque daí a gente tá muito próximo, [...], mas seria uma... boa coisa para ser implantado nas escolas [...]. (Entrevista em 19/11/2014 - grifos da pesquisadora).

\section{ENTREVISTADO.05 - R: 02}

É importante [o ensino da Língua Espanhola]. Acredito ser mais importante que o inglês porque se tem mais contato e seria mais utilizado [...] É importante porque é um município de fronteira e o país vizinho fala espanhol [...]. (Entrevista em 19/11/2014 - grifos da pesquisadora).

\section{ENTREVISTADO.02 - R: 02}

Eu acho que aqui o espanhol seria melhor, né, porque é uma língua que eles tem contato, né, que eles tem como praticar [...] (Entrevista em 10/04/2014 grifos da pesquisadora).

\section{ENTREVISTADO.09 - R: 01}

A língua espanhola seria bem viável para nós, por morar perto da fronteira [Paraguai], como disciplina. Em comparação como inglês, o espanhol é bem mais viável. (Entrevista em 19/11/2014 - grifos da pesquisadora).

Embora alguns Entrevistados compartilharem da importância da Língua Inglesa e outros não, ponderou-se ser a Língua Espanhola a mais adequada ao ensino no município de Guaíra, haja vista o contexto atual de fronteira geográfica enunciativa vivenciado pela região. Esse espaço enunciativo, permeado de contato linguístico, possibilita que os habitantes da fronteira se utilizem de ambas as línguas, tanto portuguesa quanto espanhola e inclusive do Portunhol, de modo prático e integrativo, uma vez que "o espanhol é a segunda língua mais usada no comércio internacional, especialmente no eixo que liga a América do Norte, Central e do Sul" (SEDYCIAS, 2005, p. 36 - grifos nossos).

O Entrevistado 05, através do recorte 03, reforça o ensino da Língua Espanhola de duas maneiras, a primeira enquanto acréscimo de conhecimento à bagagem dos alunos e a segunda, por ser o idioma mais falado na América, a se considerar o número de falantes:

\section{ENTREVISTADO.05 - R: 03}

[...] Conhecimento nunca é demais, pois se fazer uma viagem ajuda porque a América fala espanhol. (Entrevista em 19/11/2014 - grifos da pesquisadora).

O Entrevistado 05, no recorte 03, enfatiza a prática da Língua Espanhola ao considerar o contexto geográfico em que o Brasil se encontra. Partindo dessa perspectiva, a condição física que determina o limite entre os territórios de cada nação já justifica a presença da 
Língua Espanhola, não apenas no município de Guaíra, mas também a nível nacional, uma vez que à exceção de Suriname, Guiana e Guiana Francesa, todos os países fronteiriços com o Brasil "têm o espanhol como língua oficial, [...]. Isso é tão importante não somente do ponto de vista econômico e comercial (p.ex., Mercosul) como também cultural e até pessoal, já que compartilhamos culturas muito similares" (SEDYCIAS, 2005, p. 39).

Já o Entrevistado 07, no recorte 03, reforça a valorização do ensino e da aprendizagem da Língua Espanhola sob o enfoque da interação comunicativa, haja vista a sua realidade de contato linguístico dentro da escola:

\section{ENTREVISTADO.07- R: 03 \\ [...] Seria interessante [ter o espanhol]? Seria, porque a gente tem uma demanda grande de alunos que falam isso, né, e a gente tem essa intermediação, que não é tão forte, com o Paraguai, mas seria interessante ter a língua espanhola, mas também não é de interesse público, né. [...]. (Entrevista em 19/11/2014 - grifos da pesquisadora).}

A partir do exposto pelo Entrevistado 07, recorte 03, comprova-se a presença de alunos falantes da Língua Espanhola nas escolas guairenses e o descaso com políticas públicas de incentivo ao bilinguismo fronteiriço. Rajagopalan (2013), realça que, na maioria das vezes, as políticas linguísticas em vigor são resultados de ações que vêm de cima para baixo. Muitas vezes estas ações não consideram as particularidades locais e reais da comunidade e ainda que "qualquer grupo [poça] elaborar uma política lingüística [...] apenas o Estado tem o poder de e os meios de passar ao estágio do planejamento, de pôr em prática suas escolhas" (CALVET, 2007, p. 21). Diante disso:

\section{ENTREVISTAD0.02 - R: 01}

Teria que ser todas as escolas... exigirem [...]. (Entrevista em 10/04/2014 grifos da pesquisadora).

Nessa perspectiva, se todas as escolas exigissem a oferta da Língua Espanhola seria possível que "todos do município [...] tivessem o mesmo projeto" (ENTREVISTADO 13, 2014). O ato de exigir seria uma forma de posicionamento e uma possibilidade de construção conjunta de um planejamento político-linguístico condizente com a realidade guairense.

Acresce-se que durante a pesquisa, dois (02), dos quinze (15) Entrevistados, mostramse mais favoráveis ao ensino da Língua Inglesa: 
Bom, essa é minha opinião particular: hoje em dia o mundo fala inglês, o mundo gira em torno do inglês, qualquer lugar que você vai, você fala o inglês. [...] Então, vários lugares que já viajaram [amigas] quando você chega lá vai falar o espanhol a pessoa não sabe, mas falou o inglês não tem, tem como errar. [...] Mas o ideal seria, assim a meu ver, o inglês ainda, ainda mais até que o espanhol, apesar da gente ter a proximidade aqui com a fronteira [Paraguai]. (Entrevista em 10/04/2014 - grifos da pesquisadora).

\section{ENTREVISTADO.01 - R: 04}

O inglês é a língua mundial. São as classes com maior poder aquisitivo que se utilizam e preferem o inglês. Olhando a nossa realidade, são as classes menos favorecidas que se utilizam do espanhol. (Entrevista em 10/04/2014 grifos da pesquisadora).

Tanto a posição do Entrevistado 07, recorte 02, como a do Entrevistado 01, recorte 04, são resultantes de seus pontos de vista, da forma como avaliam a importância das Línguas Estrangeira e, como tal, a opinião de cada um deve ser respeitada, pois retrata a maneira pela qual enxergam o mercado linguístico atual. Se na atualidade a Língua Inglesa adquiriu o status de língua universal, sendo tão importante quanto evidencia os dois participantes, foi porque passou por um processo que a reconheceu como tal.

No entanto, Sedycias (2005) faz a ressalva de que a condição atual da Língua Espanhola não difere muito da Língua Inglesa, pois a posição que essa "ocupa no mundo hoje é de tal importância que quem decide ignorá-la não poderá fazê-lo sem correr o risco de perder muitas oportunidades de cunho comercial, econômico, cultural, acadêmico ou pessoal" (SEDYCIAS, 2005, p. 36). Ao alertar sobre a importância que a Língua Espanhola vem adquirindo na atualidade, o autor citado destaca o status de língua global que a mesma está conquistando.

Oliveira (2010, p. 25), complementa que

\footnotetext{
Estes permanentes rearranjos dos mercados linguísticos, dados pela mudança rápida de contextos para o ingresso e a permanência das línguas nos circuitos de produção, seja em espaços sub-nacionais, seja no âmbito dos países, seja nos novos blocos econômicos e políticos, nos permitem entender melhor as políticas linguísticas em curso direcionam nosso olhar para o que poderíamos chamar de reposicionamento dos centros de gestão de línguas. Este reposicionamento dos agentes políticolinguísticos decorre da necessidade de estarem atentos para perceber os contextos altamente mutantes e as oportunidades altamente fugidas para a manutenção ou ampliação dos âmbitos de uso das línguas.
}

Ao tratar do lugar das línguas, o estudioso destaca a mobilidade das línguas para atender aos imperativos mais emergentes. Se hoje a Língua Espanhola tem se equiparado à 
Língua Inglesa, foi porque se desenvolveram situações que suscitaram a utilização da mesma. Quando o pesquisador evidencia o reposicionamento das línguas, faz um alerta à necessidade de ampliação dos circuitos de uso das línguas para atender à demanda dos usuários.

Nesse contexto de fronteira geográfica enunciativa, a Língua Espanhola tem tanta importância quanto a Língua Inglesa, como pode ser observado nas seguintes falas:

\section{ENTREVISTADO.13 - R: 02}

Se de repente pudesse acontecer os dois [espanhol e inglês], pensando nesta questão deles saírem daqui para o fundamental II, é que lá é o inglês. Então eu acho interessante... ter os dois... ou no fundamental I ter o espanhol e depois o inglês [...], mas acho que seria interessante sim adotar línguas. (Entrevista em 17/11/2014 - grifos da pesquisadora).

\section{ENTREVISTADO.03 - R: 03}

Olha, o Espanhol... e o inglês. [...] O principal seria assim..., pelo nosso contexto da localidade, seria muito interessante o espanhol e o inglês, porque isso é uma quest., i, né, de outras, outras crianças tem, que é a mais falada. E o espanhol também, porque hoje em dia, né, tem prova que a gente vai fazer quando adulto que só tem o inglês, (?), tem prova que tem as duas opções, então, seria..., já facilitava [...]. (Entrevista em 19/11/2014 - grifos da pesquisadora).

\section{ENTREVISTADO.12 - R: 02}

O espanhol é importante... porque nós... devido a fronteira, devido a nós termos contato, né, e... a língua inglesa também é importante... porque hoje em dia você tem... você tem que falar, né, você tem que... nós assim... que nós temos que... fazer cursos. Igual mesmo, eu não faço, mas para os meus filhos... eu quero que eles façam inglês..., espanhol, porque é importante, né, eles conhecerem outras línguas e quando eles precisarem... eles vão saber, né. Então é importante. (Entrevista em 17/11/2014 - grifos da pesquisadora).

\section{ENTREVISTADO.11 - R: 01}

[...] Porque assim, as duas línguas mais faladas é o inglês e o espanhol. Então eu acho que seria interessante junto com... as matérias específicas assim... trabalhar as duas línguas, inglês e espanhol... (Entrevista em 12/11/2014 - grifos da pesquisadora).

\section{ENTREVISTADO.10 - R: 02}

No caso o espanhol, a língua materna o português e o inglês. Isso seria o necessário. [por que você acha que deveria ser as três?] Bom, o espanhol devido à fronteira, o inglês por ser $a$, a linguagem... como se diz?... mundial, universal e o português a língua materna mesmo. E apesar de falar... ser uma linguagem que já deveria saber... e a gente não, não tem... acaba não sabendo falar... né, falar corretamente, a gente fala mais aquela linguagem coloquial, mas que deveria ter [...]. (Entrevista em 19/11/2014 grifos da pesquisadora). 
Eu acho que o espanhol, igual eu falei pra você e... também... o inglês também eu acho, e também a língua guarani, porque aqui a gente tem as aldeia que estão a volta e também recebe crianças do Paraguai que vem estudar. Pra gente eu acho... que seria uma boa [...]. (Entrevista em 19/11/2014 - grifos da pesquisadora).

Os seis recortes citados pelos participantes ressaltam a validade e a importância das Línguas Estrangeiras na escola, em especial do ensino conjunto da Língua Espanhola e da Língua Inglesa, ambas enquanto disciplinas curriculares. Nesse sentido, os participantes 13, 03, 12, 11, 10 e 04, por meio dos recortes anteriores, discutem uma abordagem que já é realidade em uma das escolas particulares:

\section{ENTREVISTADO.16 - R: 01}

[...] [Vocês tem o inglês e o espanhol junto?] $O$ inglês e o espanhol... em aulas diferentes. [ $\mathrm{Na}$ grade as duas línguas?] Sim, as duas línguas [...]. (Entrevista em 12/11/2014 - grifos da pesquisadora).

O Entrevistado 16 esclarece que a escola (privada) em que trabalha oferece a Língua Espanhola em conjunto com a Língua Inglesa do $1^{\circ}$ ao $9^{\circ}$ anos do Ensino Fundamental I e II, e justifica que cada escolha se deve ao contexto, como ressalta no recorte 02 :

[...] O inglês ele é obrigatório... então a escola precisa ter na sua grade. A opção pelo espanhol é principalmente por esse... estarmos na fronteira, por termos alunos... né, que falam espanhol, por termos também... o país vizinho que eles tem que estar... que nossos alunos tem contato e precisam estar usando [a língua espanhol]. Então, por ser um país... por ser fronteira... e usa a língua... Então, a opção foi realmente trabalhar o que seria de importância para o contexto de nossos alunos. Então o inglês, ele é importantíssimo também porque é uma linguagem, universal, mas o espanhol por fazer parte do contexto de vida deles. (Entrevista em 12/11/2014 - grifos da pesquisadora e o sublinhado é a ênfase dada pelo Entrevistado).
}

É evidente no enunciado do Entrevistado 16, recorte 02, a importância que se aplica à Língua Espanhola neste âmbito de ensino particular, uma vez que considera o contato linguístico com o Paraguai e a presença de alunos paraguaios no colégio, como fatores que predispõem o ensino dessa Língua Estrangeira na instituição. Sendo assim, o "fato de sermos vizinhos é um motivo a mais para aprendermos sua língua e nos familiarizarmos com sua cultura" (SEDYCIAS, 2005, p. 39). 
Ao destacar que ofertam as duas línguas, Língua Espanhola e Língua Inglesa, O Entrevistado 16, no recorte 03, faz a ressalva de que:

\section{ENTREVISTADO.16 - R: 03}

[...] $O$ inglês e o espanhol tem que caminhar junto [...]. (Entrevista em $12 / 11 / 2014$ - grifos da pesquisadora).

O enunciado 03, do Entrevistado 16, complementa o que propuseram os Entrevistados $13,03,12,11,10$ e 04 , nos enunciados anteriores, ao sugerirem a oferta e o ensino das duas Línguas Estrangeiras nas escolas municipais. Essa postura voltada para o plurilinguismo reforça e sugere uma conduta mais engajada entre o poder público e a comunidade, bem como uma política linguística planejada em detrimento dos sujeitos atendidos e da realidade vivenciada, uma vez que são diversos os fatores em prol do ensino e da aprendizagem da Língua Espanhola na cidade guairense.

Desse modo, destaca-se a relevância de uma abordagem de cunho aplicado, que envolva toda a problemática advinda da contemporaneidade, orientada não por teorias, mas sim por problemas, que vão além das fronteiras da linguagem e do contexto social.

\section{Considerações finais}

Há, portanto, uma emergência na conscientização e no reconhecimento da pluralidade linguístico-cultural vivenciada no município de Guaíra, haja vista o contato linguístico existente entre a Língua Portuguesa e a Língua Espanhola. No que se refere à relação entre as culturas brasileiras e, sobretudo, paraguaias, a integração e o respeito contribuem para atender tanto as demandas emergentes de um mundo globalizado quanto às particularidades locais.

Assim, dentro do que se pôde descrever neste texto, pode-se dizer que os Entrevistados demonstraram interesse pela oferta da Língua Espanhola ao refletirem sobre as particularidades do município e da presença de alunos hispano falantes nas salas de aula, bem como da possibilidade de melhoria na comunicação entre os usuários das Línguas Portuguesa e Espanhola, tanto no comércio como no dia a dia, seja no contato pessoal ou profissional.

Desse modo, é preciso pensar em ações políticas vindas do Estado e/ou do Município em parceria com a Comunidade, para que todos possam usufruir das mesmas oportunidades de ensino, dirimindo as diferenças refletidas tanto na língua como na cultura e no acesso ao saber institucionalizado. 


\section{REFERÊNCIAS}

CALVET, L. J. As políticas lingüísticas. Tradução de Isabel de Oliveira Duarte, Jonas Tenfen e Marcos Bagno. São Paulo: Parábola, 2007.

CAMPIGOTO, José A. Hermenêutica da fronteira: a fronteira entre o Brasil e o Paraguai. Florianópolis, 2000. Tese de Doutorado em História. Universidade Federal de Santa Catarina. Centro de Filosofia e Ciências Humanas. Florianópolis, 2000.

Narradores de fronteira: malhas da pré-compreensão. Anais do Simpósio Nacional em Ciências Humanas - Universidade e Sociedade. UNIOESTE, Marechal Cândido Rondon, PR: EDUNIOESTE, junho/2006, p. 153-157.

HAMEL, Rainer E. Direitos linguísticos como direitos humanos: debates e perspectives. In OLIVEIRA, Gilvan M de (orgs.). Declaração universal dos direitos lingüísticos. Campinas, SP: Mercado de Letras, 2003, p. 47-80.

LEFFA, Vilson J. Aspectos políticos da formação do professor de línguas estrangeiras. In LEFFA, Vilson J. (org.). O professor de línguas estrangeiras: construindo a profissão. Pelotas, 2001, v. 1, p. 335-355.

OLIVEIRA, Gilvan M. de. Política Linguística na e para além da Educação Formal. Estudos linguísticos XXXIV, p. 87-94, 2005. Disponível em: <http://etnolinguistica.wdfiles.com/local-files/journal\%3Aestudos/oliveira_2005_politica.pdf> Acesso em set. 2013.

. "O lugar das línguas: a América do Sul e os mercados linguísticos na nova economia".

Revista Synergies Brési, n. Especial (2010), p. 21-30, 2010.

Políticas linguísticas como políticas públicas. 2013. Disponível em: <http://eipol.org/wp-ontent/uploads/2013/06/Politicas_linguisticas_e_Politicas_publicas.pdf> Acesso em set. 2013.

PEREIRA, Maria Ceres. O português e as línguas nas fronteiras: desafios para a escola. Revista Siple. Ed. 2. Ano 2, n. 1. Brasília: 2011. Disponível em: <http://www.siple.org.br/ index.php?option=com_content\&view=article\&id=172:3-o-portugues-e-as-linguas-nas-

fronteiras--desafios-para-a-escola\&catid=57:edicao-2\&Itemid=92> Acesso em nov. De 2014. RAJAGOPALAN, Kanavillil. Política linguística: do que é que se trata, afinal? In NICOLAIDES, Christine et al. (Orgs). Política e políticas lingüísticas. Campinas, SP: Pontes, 2013, p, 19-42.

RIBEIRO, Simone B. C. Língua(s) de fronteira: o ensino da Língua Espanhola em Guaíra, Paraná. 2015. 259 p. Tese (Doutorado em Letras) - Universidade Estadual do Oeste do Paraná. Cascavel, 2015.

SEDYCIAS, João. Por que os brasileiros devem aprender espanhol? In: SEDYCIAS, João (Org.). O ensino do espanhol no Brasil: passado, presente, futuro. São Paulo: Parábola Editorial, 2005, p. 35-44.

SILVA, K. A.; SANTOS, L. I. S.; JUSTINA, O. D. Entrevista com Kanavillil Rajagopalan: ponderações sobre linguística aplicada, política linguística e ensino-aprendizagem. Revista de Letras Norte@mentos - Revista de Estudos Linguísticos e Literários. Ed 08 - Estudos Linguísticos 2011/02. Disponível em: <http://projetos.unemat-net.br/revistas_eletronicas/ index.php/norteamentos> Acesso em março de 2014.

STURZA, Eliana R. Línguas de Fronteira e Políticas de línguas: uma história das idéias linguísticas. Campinas, 2006. Tese de Doutorado. Campinas. UNICAMP, 2006.

. No tempo e no espaço: mapeando as línguas de fronteira. In: I CIPLOM, de 19 a 22 de outubro de 2010. Foz do Iguaçu, 2010, p. 1-7. Disponível em: <http://www.apeesp.com.br/ ciplom/Arquivos/artigos/pdf/elianasturza.pdf> Acesso em set. de 2013. 
VON BORSTEL, Clarice N. Políticas linguísticas e educacionais em situações de línguas em/de contato. LLJournal, v. 8, n. 1, p.1-10. 2013. Disponível em: <http://ojs.gc.cuny.edu/index.php/ lljournal/article/view/1365/1452> Acesso em jun. 2014.

Recebido em: 31/03/2017. Aceito em: 19/06/2017. 